\title{
Electrochemical Elucidation of Nano-Functions of Metal Complexes and the Application to Nanodevices
}

\author{
Masa-aki Haga*
}

Received September 21, 2018

\begin{abstract}
Surface modification using redox-active units is one of the important subjects in molecular electrochemistry. During the past two decades, many functional nanostructures with redox activity have been prepared and examined the new functionalities. Based on the solution chemistry of protonresponsive ruthenium complexes containing benzimidazole derivates, I have developed the coordination $\mathrm{LbL}$ growth of redox-active $\mathrm{Ru}$ complexes toward molecular functional devices. To control the molecular orientation of the redox-active complexes on a transparent conductive ITO surface, tetrapod phosphonic acid anchor groups have been introduced in the rod-shaped ruthenium dinuclear complexes, resulting in the formation of well-ordered surface coordination network structures in a nanometer scale. Electrochemical functions of the nanostructures such as molecular switches, diodes, and memories have been achieved.
\end{abstract}

\section{Introduction}

Molecular electrochemistry of metal complexes has been developed to clarify and elucidate the redox reaction mechanism of metal complexes. By the aid with electrochemical methods such as cyclic voltammetry, spectroelectrochemistry and digital simulation of $\mathrm{CV}$, the understanding of redox reactions for metal complexes becomes deeper and broader, which leads to a new avenue for designing the redox reactions by tuning the redox potentials of metal complexes. Furthermore, the modification of electrode surface by redox-active molecules results in enhanced electron transfer kinetics throguh the efficient redox mediation

\footnotetext{
* Department of Applied Chemistry, Faculty of Science and Engineering, Chuo University, 1-1327 Kasuga, Bunkyo-ku, Tokyo 112-8551, Japan. E-mail: mhaga@kc.chuo-u.ac.jp
}

between the electrode and the substate. In recent years, as the surface modification, molecular architectures including surface metal-organic frameworks (SURMOF) has paid much attention from the viewpoint of confined pore sizes and gas/ion storage abilities. ${ }^{1)} \quad$ To approach such surface MOF structures with redox activities, the layer-by-layer $(\mathrm{LbL})$ fabrication of redox-active molecules adds a fresh dimension to basic concepts such as electric double layer or tunneling/hopping electon transfer. In this review, I focus on the inorganic molecular electrochemistry and surface modication by LbL method based on redox-active metal complexes toward molecular devices.

\section{Tuning of redox potentials in $\mathrm{Ru}$ complexes} by molecular design.

Redox potentials of the metal complexes are 
determined by both central metal ion and surrounded ligands around metal ion. In order to predict the redox potentials for the molecular design of metal complexes, the physical parameterization method has been requisite. When the substitution of bpy ligand in $\left[\mathrm{Ru}(\mathrm{bpy})_{3}\right]^{2+}$ (bpy= 2,2'-dipyridine) to L provides a series of $\left[\mathrm{Ru}(\mathrm{bpy})_{3-\mathrm{x}}(\mathrm{L})_{\mathrm{x}}\right]^{\mathrm{n}+}$, the redox potentials of $\mathrm{Ru}(\mathrm{II} / \mathrm{III})$ were additive on the number of $\mathrm{L}, \mathrm{x}$, and the slope of the plot of $E_{1 / 2}$ vs the number of ligand $\mathrm{x}$ reflected on the $\pi$-donor/ $\pi$-acceptor proeprties. ${ }^{2)}$ Based on this ligand additivity on the redox potentials, several attempts to parameterize the electronic effect of ligand in the metal complexes as "ligand parameter" have been reported, ${ }^{3)}$ and the difinitive ligand electrochemical parameter $\mathrm{E}_{\mathrm{L}}(\mathrm{L})$ was proposed by Lever. ${ }^{4}$ and the list of $\mathrm{E}_{\mathrm{L}}(\mathrm{L})$ values is covered for over 200 ligands. By using this $\mathrm{E}_{\mathrm{L}}(\mathrm{L})$ parameter, the redox potentials of metal



Scheme 1. Chemical structures of Ru complexes 1 - 4

complexes can be predicted. We have employed benzimidazole derivates as a ligand. Benzimidazole holds a stronger $\sigma$-donor and weaker $\pi$-acceptor properties, compared to pyridine with weaker $\sigma$-donor and stronger $\pi$ acceptor properties. For example, the $E_{\mathrm{L}}$ values are given as $0.17 \mathrm{~V}$ for bezimidazole and $0.25 \mathrm{~V}$ for pyridine in tpy. Using these $E_{L}$ values, the $\mathrm{Ru}(\mathrm{II} / \mathrm{III}$ ) potential of $\mathbf{2}$ (Scheme 1) can be estimated as $+0.87 \mathrm{~V}$ vs $\mathrm{Ag} / \mathrm{AgCl}$, which is close to the observed value of $+0.86 \mathrm{~V}$ vs $\mathrm{Ag} / \mathrm{AgCl}$. On the other hand, the $\mathrm{Ru}(\mathrm{II} / \mathrm{III})$ potential of $\mathbf{1}$ exhibited $+0.26 \mathrm{~V}$ vs $\mathrm{Ag} / \mathrm{AgCl}$, from which the $E_{L}$ value for phenyl anion was derived as $-0.40 .^{5}$ This large negative $E_{L}$ value indicates the strong donation through Ru-cyclometalated bond, which induces the large increase of HOMO energy levels in the $\mathrm{Ru}$ complexes. Considering the ligand parameter, the dinuclear ruthenium complexes 5 and $\mathbf{6}$ having cyclometalated bonds in the bridging ligand have been synthesized. Since both complexes 5 and $\mathbf{6}$ showed two oneelectron redox waves at $-0.40 \mathrm{~V}$ and $0.07 \mathrm{~V}$ vs

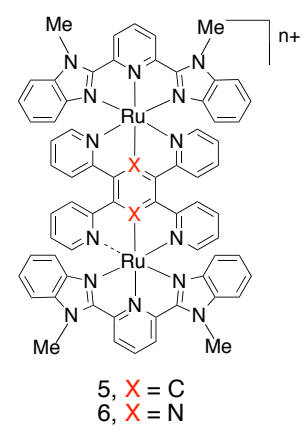

Scheme 2. Chemical structures of Ru complexes 5, 6 $\mathrm{Fc} / \mathrm{Fc}^{+}$for $\mathbf{5}$, and $+0.84 \mathrm{~V}$ and $+1.06 \mathrm{~V}$ vs $\mathrm{Fc} / \mathrm{Fc}^{+}$ for 6 . As a result, the complex 5 possessed a stable mixed-valence $\mathrm{Ru}(\mathrm{II})-\mathrm{Ru}(\mathrm{III})$ state at the ambient condition in the air.

\section{Proton-responsive Ru complexes.}

PCET square scheme. Coordinated benzimidazole/imidazole ligand on metal complexes often acts as a Bronsted acid, and an acid-base reaction in aqueous solution takes place. When a redox-active metal complex possesses such coordinated ligand, the complex often exhibits a proton-coupled electron transfer (PCET) reaction. ${ }^{6}$ We found that ruthenium complexes containing benzimidazole derivative ligands show a PCET reaction, in which the N-H imino proton movement on the coordinated benzimidazole is coupled with the 
redox reaction on the $\mathrm{Ru}$ center. ${ }^{7-11)}$ Pourbaix diagram of the ruthenium complexes can help the understanding of the relationship between redox potentials and $\mathrm{pKa}$ values in PCET reactions. From the thermodynamic cycle in $\mathrm{H}^{+} / \mathrm{e}^{-}$PCET reactions, the bond dissociation free energies (BDFEs) $\left[\mathrm{kcal} \cdot \mathrm{mol}^{-1}\right]$ are calculated by the following equation: ${ }^{12)}$

$\operatorname{BDFE}(\mathrm{RuL}-\mathrm{H})\left[\mathrm{kcal} \cdot \mathrm{mol}^{-1}\right]=$ $1.37 \mathrm{p} K \mathrm{a}+23.06\left[E^{0}\left(\mathrm{Ru}^{\mathrm{III}} \mathrm{L} / \mathrm{Ru}{ }^{\mathrm{II}} \mathrm{LH}\right)\right]+57.6$

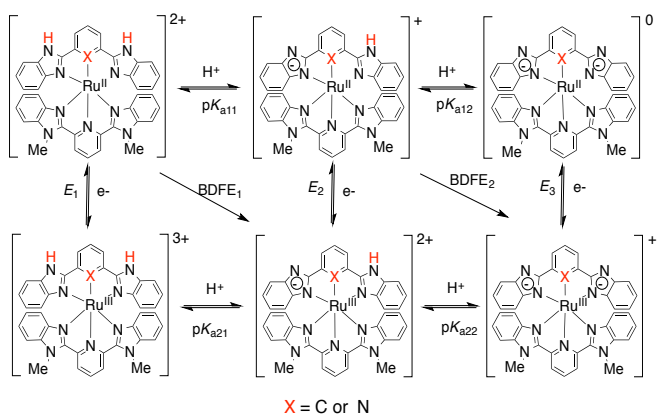

Scheme 3. $\mathrm{H}^{+} / \mathrm{e}^{-}$PCET square scheme of $\mathrm{Ru}$ complexes $\mathbf{3}, \mathbf{4}$

The $\mathrm{p} K_{\mathrm{a} 11}$ and $\mathrm{p} K_{\mathrm{a} 21}$ values for $\mathrm{Ru}^{\mathrm{II}}$ and $\mathrm{Ru} \mathrm{u}^{\mathrm{III}}$ states of complex $4(\mathrm{X}=\mathrm{N})$ are 6.31 and $<2$, and 10.91 and 6.46 for those of $3(X=C)$, respectively. The $\mathrm{BDFE}_{1}$ of the $\mathrm{N}-\mathrm{H}$ bond for $3(\mathrm{X}=\mathrm{C})(62.75$ $\left.\mathrm{kcal} \cdot \mathrm{mol}^{-1}\right)$ was lower than that for $4(\mathrm{X}=\mathrm{N})$ $\left(70.8 \mathrm{kcal} \cdot \mathrm{mol}^{-1}\right)$ because of the high electron densities by the cyclometallated $\mathrm{Ru}-\mathrm{C}$ bond in $\mathbf{3}$. Therefore, the $\mathrm{p} K_{\mathrm{a}}$ values for $\mathbf{3}$ are larger than those for 4 . In addition, the deprotonation induced the large potential shift to the negative potential direction. Therefore, protonation/deprotonation can be used as an external stimulus for the potential tuning in the redox-active complexes.

Proton-induced switching in dinuclaer and tetranuclear complexes. Fundamental understanding of intramolecular electron transfer events in dinuclear metal complexes have attracted much interest from the viewpoint of the electronic conduction in molecular electronic devices such as molecular wires and switches. In particular, mixed-valence states hold great significance to determine the controlling factors for the intramolecular electron transfer in the dinuclear complexes. ${ }^{28)}$

Dinuclear $R \boldsymbol{R}$ complexes. In order to introduce the switching function by external stimuli in the mixed-valence $\mathrm{Ru}$ complexes, we have synthesized novel dinuclear $\mathrm{Ru}$ complexes having bis(benzimidazolyl) bridging ligand (see Scheme 4). ${ }^{8)}$ The oxidative electrochemistry of dinuclear $\mathrm{Ru}$ complexes 7 $\mathbf{9}$ strongly depend on the solution $\mathrm{pH}$. For complex 7, two closely located one-electron oxidation waves were observed, in which the waves were resolved into two succesive one-electron processes having $E_{1}$ and $E_{2}$ as shown in eq (2) and the potential of each wave was shifted to the negative direction by an increase of $\mathrm{pH}$ (Fig. 1). $[R u(I I)-R u(I I)] \underset{\mathrm{e}^{-}}{\stackrel{E_{1}}{\longrightarrow}}[R u(I I)-R u(I I I)] \stackrel{\frac{E_{2}}{\mathrm{e}^{-}}}{\longrightarrow}[R u(I I I)-R u(I I I)]$

Furthermore, the separation between $E_{1}$ and $E_{2}$ became larger with increasing the $\mathrm{pH}$. By the deprotonation on the bridging ligand (BL) of 7 , the intervalence charge transfer (IVCT) band around $5880 \mathrm{~cm}^{-1}$ was intensified and shifted to a

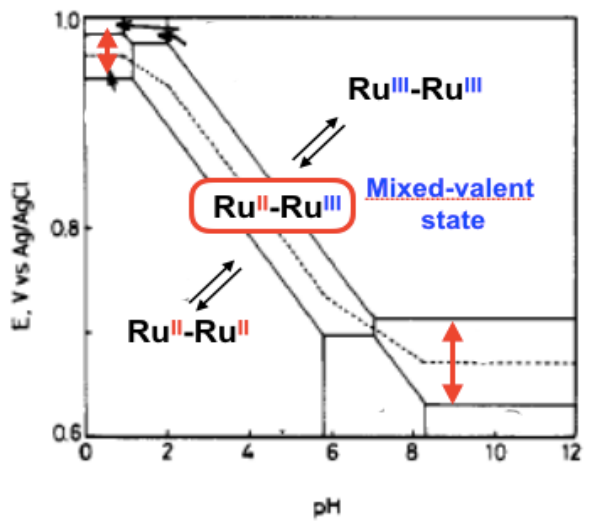

Fig.1. Pourbaix diagram of dinuclear $\mathrm{Ru}$ complex 7 . (Modified from Ref. 8) 
lower energy, indicating the strengthening of the $\mathrm{Ru}-\mathrm{Ru}$ interaction in the mixed-valence state. ${ }^{8}$ On the other hand, complexes 8 and 9 in the mixed-valence state exhibited the weakening of the Ru-Ru interaction by the deprotonation on the BL ligand, ${ }^{11)}$ which is in a sharp contrast with 7 . The difference between two types of complexes derived from the electronic orbital mixing between $\pi$ or $\pi^{*}$ BL orbitals and $\mathrm{Ru}(\mathrm{II}) \mathrm{d} \pi$ or $\mathrm{Ru}(\mathrm{III}) \mathrm{d} \pi$ orbitals; i.e., the $\mathrm{Ru}(\mathrm{III}) \mathrm{d} \pi$-BL $\pi$ orbital mixing is predominant for 7 , while the $\mathrm{Ru}(\mathrm{II}) \mathrm{d} \pi$-BL $\pi *$ orbital mixing was governed in the mixed-valence state of both 8 and 9. ${ }^{11)}{ }^{13)}$ As a consequence, proton transfer acts as an exernal



Scheme 4. Chemical structures of Ru complexes 7-9.

stimulus to modulate the mixed-valence $\mathrm{Ru}(\mathrm{II})$ $\mathrm{Ru}(\mathrm{III})$ interaction. This result was extended into the metallopolymer having polymeric (2benzimidazolyl)pyridine BL ligand. ${ }^{14)}$

\section{Dendrimee-type tetranuclear $\mathrm{RuOs}_{3}$ complex.}

The complex 10, [\{Os(bpy $)_{2}\left(\right.$ bbbpyH $\left.\left.\left.\mathrm{H}_{2}\right)\right\}_{3} \mathrm{Ru}\right]^{8+}$, is composed of a central $\mathrm{Ru}^{\mathrm{II}}$ ion coordinated by three (2-benzimidazolyl)pyridine ligands, and three connected peripheral Os(bpy) ${ }_{2}$ units. ${ }^{15)}$ The central $\mathrm{Ru}^{\mathrm{II}}$ ion was surrounded by protonresponsive three benzimidazole moieties, while the peripheral Os ions possessed only one benzimidazole group. The fully-protonated $\mathbf{1 0}$ showed two oxidation waves at $+0.38\left(3 \mathrm{e}^{-}\right)$and $+0.71 \mathrm{~V}$ vs $\mathrm{Fc} / \mathrm{Fc}^{+}\left(1 \mathrm{e}^{-}\right)$, however upon the full

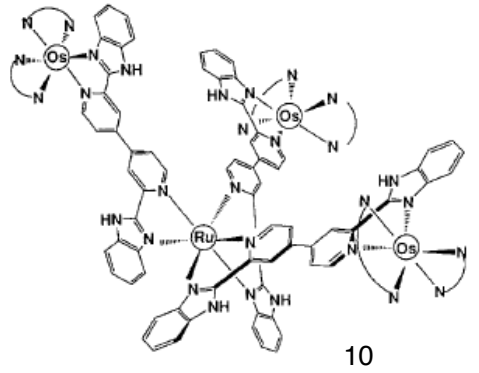

Scheme 5. Chemical structures of tetranuclear $\mathrm{RuOs}_{3}$ complex 10. (center ion; $\mathrm{Ru}$, peripheral ions; Os, $\mathrm{N}^{\wedge} \mathrm{N}$; 2,2’- bipyridine)

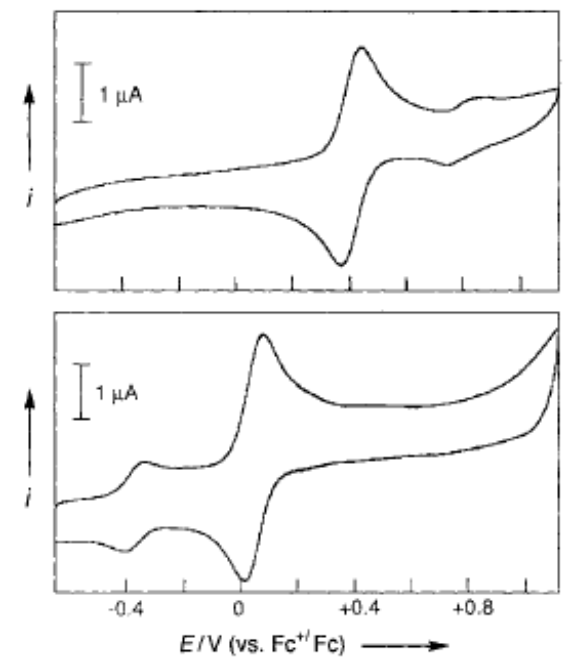

Fig. 2. Cyclic voltammograms of fully protonated $\mathrm{RuOs}_{3}$ complex $\mathbf{1 0}$ (top) and deprotonated form in $\mathrm{CH}_{3} \mathrm{CN}\left(0.1 \mathrm{M} \mathrm{TBABF}_{4}\right.$ )(bottom). (Reprinted with the permission from ref. 15. Copyright 1996, VCH)

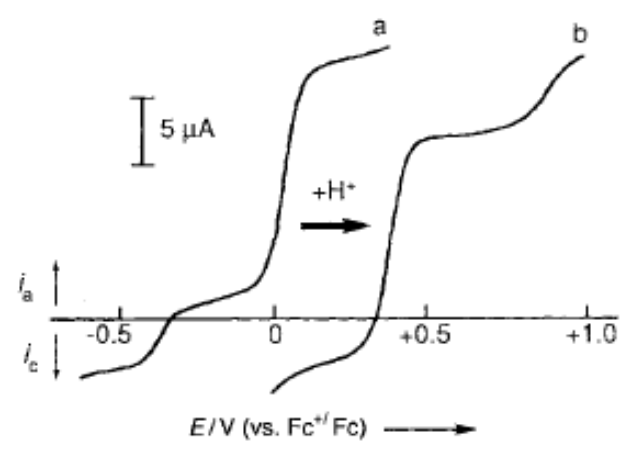

Fig. 3. RDE voltammograms of (a) the one-electron oxidized deprotonated RuOs 3 complex 10 in $\mathrm{CH}_{3} \mathrm{CN}$ $\left(0.1 \mathrm{M} \mathrm{TBABF}_{4}\right)$ and (b) after the addition of $1 \mathrm{mM}$ $\mathrm{HClO}_{4}$. (Reprinted with the permission from ref. 15 . Copyright 1996, VCH) 
deprotonation to $\left[\left\{\mathrm{Os}(\mathrm{bpy})_{2}(\mathrm{bbbpy})\right\}_{3} \mathrm{Ru}\right]^{2+}$, the order of the pattern of two oxidation waves became reversed, and two waves were shiftd to negative potential direction of $-0.34 \mathrm{~V}\left(1 \mathrm{e}^{-}\right)$and $+0.06 \mathrm{~V}$ vs $\mathrm{Fc} / \mathrm{Fc}^{+}\left(3 \mathrm{e}^{-}\right)$, as shown in Fig. 2. After the one-electron oxidation of the deprotonated complex $\left[\left\{\mathrm{Os}(\mathrm{bpy})_{2}(\mathrm{bbbpy})\right\}_{3-}\right.$ $\mathrm{Ru}]^{2+}$ at $-0.2 \mathrm{~V}$, the rotating disk electrode (RDE) voltammogram in $\mathrm{CH}_{3} \mathrm{CN}$ showed one-electron central $\mathrm{Ru}^{\mathrm{III}}$ to $\mathrm{Ru}^{\mathrm{II}}$ reduction wave as a cathodic current, followed by the three-electron peripheral $\mathrm{Os}^{\mathrm{II}}$ to Os ${ }^{\mathrm{III}}$ oxidations. When the proton was added into this solution, the order of the $3 \mathrm{e}^{-}$and $1 \mathrm{e}^{-}$processes was switched, and furthermore a small part of the cathodic current was involved in the $3 \mathrm{e}^{-}$process in which the other current remained as the anodic current (Fig. 3). The change of this RDE voltammogram indicates that the proton-induced intramolecular electron transfer occurred from the peripheral Os ${ }^{\mathrm{II}}$ site to the central $\mathrm{Ru}^{\mathrm{III}}$ moiety. ${ }^{15)}$

\section{Fabrication of layer-by-layer (LbL) films based on redox-active $R u$ complexes.}

Surface functionalization is one of the longstanding researh challenges in a wide range of fields such as corrosion, catalysis, adhesion, organic electronics, etc in physical and materials chemistry. ${ }^{16)}$ Our approach to surface modification is based on the self-assembled attachment of redox-active metal complexes with

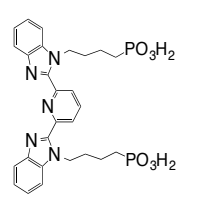

LP



$\mathrm{XP}$

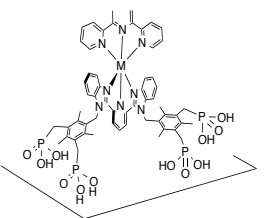

Scheme 6. Chemical structures of tridentate 2,6bis(benzimidazol-2-yl)pyridine with multipod phosphonic acid anchors.

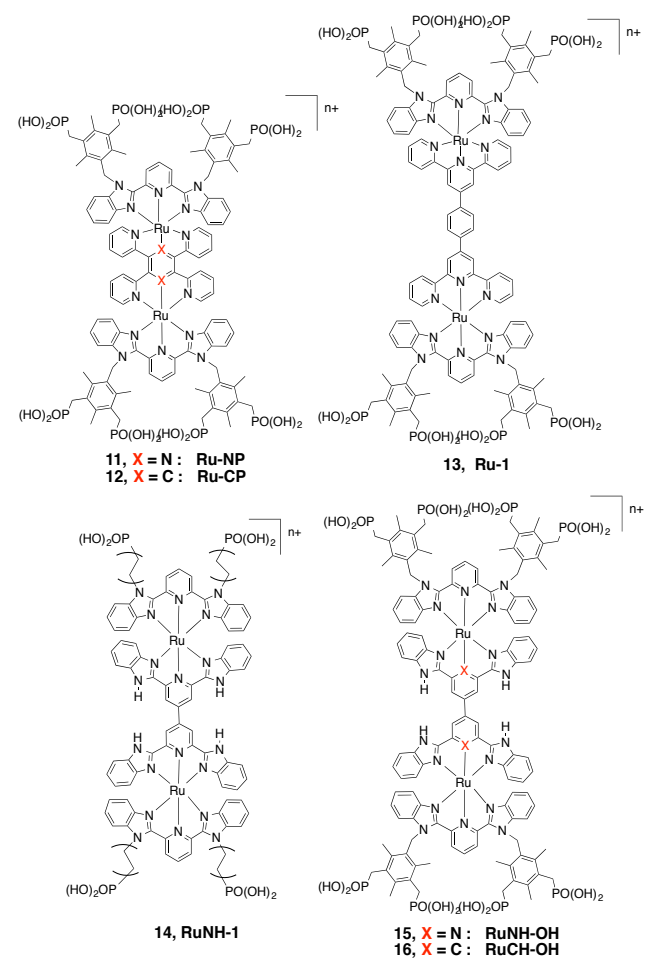

Scheme 7. Chemical structures of dinuclear $\mathrm{Ru}$ complexes 11 -16 with phosphonic acid groups.

anchoring groups on an electrode surface in order to extend our solution functional chemistry to molecular devices on an electrode surface. Since the formation of self-assembled monolayers (SAMs) on a solid surface is a wellestablished method to modify the electrode surface, the selection of functional groups plays an important role. While the combination of organic thiol with gold surface or organic silane with $\mathrm{SiO}_{2}$ on silicon wafer has been commonly used, ${ }^{17)}$ we selected a flattened indium-tin oxide (ITO) surface because of its transparency and relatively high conductivity. As for an anchoring group onto an ITO, phosphonic acid was used, which is also a linker group to connect another complex layer by metal coordination. Mallouk et al. has reported the construction of 
well-ordered layered metal phosphonate structures on the surface, ${ }^{18)-20)}$ which inspired us and others to fabricate the redox-active coordination network structures on the metal oxide surfaces. ${ }^{21)}$ Recently, several reviews regarding phosphonate films on the metal oxide surface have been published. ${ }^{22)}$ 23)

We have designed several multipod phosphonic acid anchors for surface functionalization, which are shown in Scheme 6 . In order to keep the molecular orientation rigid on the surface,tetrapodal phosphonic acid ligand XP was introduced, in which four phosphonic acid groups are branching from two mesityl groups on tridentate 2,6-bis(benzimidazol-2-yl)pyridine. Because of the restricted rotation around $\mathrm{C}$ (mesityl)-C(methylene)-N(benzimidazole)

bonds, 2-benzimidazolyl plane is oriented perpendicular to the mesityl ring, resulting in the four phosphonic acid groups are directed to the metal oxide surface. The auxiliary tridentate ligand in bis(tridentate) octahedral metal complexes consequently holds the vertical orientation to the surface normal. Similarly, several multipod anchor ligands have also been reported. ${ }^{24)-26)}$ A series of rod-shaped dinuclear $\mathrm{Ru}$ complexes 11-16 containing the ligand XP have been synthesized as shown in Scheme 7, in which tetrapod phosphonic acid groups exist at both ends and act as not only anchoring groups but also linker groups to connect the another complex unit through coordination bonds.

\section{ET events in multilayer films. Surface} immobilization of the Ru complex on an ITO electrode has been achieved by a simple immersion of an ITO electrode into the aqueous solution of the $\mathrm{Ru}$ complex adjusting to $\mathrm{pH} 4 \sim 6$ for $3 \sim 5 \mathrm{~h}$, followed by rinsing with water and

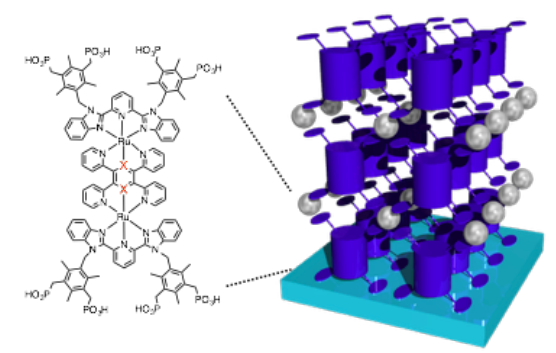

Scheme 8. Schematic representation of coordination LbL multilayer film composed of dinuclear Ru complex $\mathbf{1 1}$ or $\mathbf{1 2}$ (rod shape with anchor and linker arms) and zirconium ion (ball shape).

dried, resulting in the formation of a primer layer. Using this primer layer substrate, the multilayer film was grown in a layer-by-layer (LbL) manner by the successive immersion of the ITO substrate into $\mathrm{ZrOCl}_{2}$ aqueous solution and the Ru complex. The layer growth of the multilayer was monitored by UV-vis spectra and cyclic voltammetry(CV). Upon the increase in the number of layers, the linear increase in absorbance on UV spectra was observed. Fig. 4 shows the oxidative cyclic voltammograms of the LbL multilayer films of complex 11 with various layer numbers,
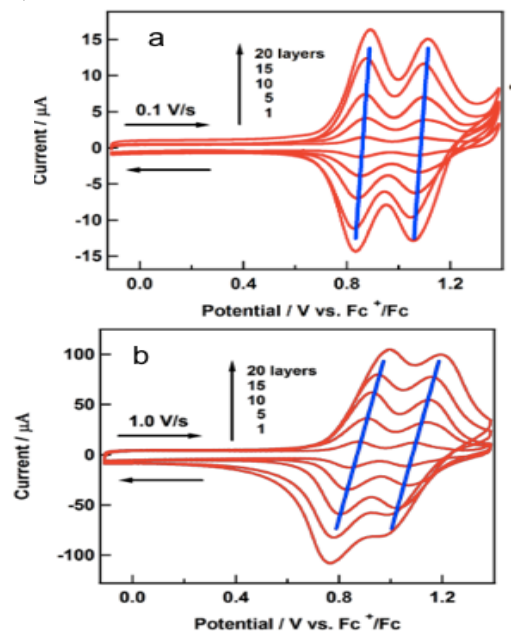

Fig. 4. Cyclic voltammograms of $\mathrm{ITO} \|(\mathbf{1 1})_{\mathrm{n}}$ in $\mathrm{CH}_{3} \mathrm{CN}$ $\left(0.1 \mathrm{M} \mathrm{HClO}_{4}\right)$ with various layer numbers; $\mathrm{n}=1,5,10$, 15, and 20. Scan rate: (a) $0.1 \mathrm{~V} \cdot \mathrm{s}^{-1}$ and (b) $1 \mathrm{~V} \cdot \mathrm{s}^{-1}$. 
ITO $\|(\mathbf{1 1})_{\mathrm{n}}(\mathrm{n}=1,5,10,15$, and 20$)$, at the scan rates of (a) $0.1 \mathrm{~V} \cdot \mathrm{s}^{-1}$ and (b) $1 \mathrm{~V} \cdot \mathrm{s}^{-1}$, in which two waves were observed at $+0.83 \mathrm{~V}$ and $+1.04 \mathrm{~V}$ vs $\mathrm{Fc} / \mathrm{Fc}^{+}$, which were assigned to the succesive oneelectron $\mathrm{Ru}^{\mathrm{II}}-\mathrm{Ru}^{\mathrm{II}} / \mathrm{Ru}^{\mathrm{II}}-\mathrm{Ru}^{\mathrm{III}}$ and $\mathrm{Ru}^{\mathrm{II}}-\mathrm{Ru}^{\mathrm{III}} / \mathrm{Ru}^{\mathrm{III}}$ $\mathrm{Ru}^{\text {III }}$ oxidation processes. The peak separation became larger with increasing the scan rate, indicating the contribution of interlayer ET kinetics. The dependence of the heterogeneous ET rates, $k_{\text {app, }}$ on the layer numbers were determined by potential-step chronoamperometry(PSCA), of which results are listed in Table 1. ${ }^{27}$

Table 1. Heterogeneous ET rates, $k_{\text {app, }}$ of mutilayer films on ITO. ${ }^{\text {a }}$

\begin{tabular}{lll}
\hline \multirow{2}{*}{$\begin{array}{l}\text { Number of } \\
\text { layers, } \mathrm{n}\end{array}$} & \multicolumn{2}{c}{$k_{\mathrm{app}} / s^{-1}$} \\
\cline { 2 - 3 } & $\mathrm{ITO} \|(\mathbf{1 1})_{\mathrm{n}}$ & $\mathrm{ITO} \|(\mathbf{1 2})_{\mathrm{n}}$ \\
\hline 1 & 497 & 235 \\
3 & $-{ }^{\mathrm{b}}$ & 92.0 \\
5 & 152 & 44.0 \\
7 & $-{ }^{\mathrm{b}}$ & 83.0 \\
10 & 44.0 & $-{ }^{\mathrm{b}}$ \\
15 & 10.0 & - \\
\hline
\end{tabular}

${ }^{\mathrm{a}} \mathrm{In} \mathrm{CH}_{3} \mathrm{CN}\left(0.1 \mathrm{M} \mathrm{HClO}_{4}\right) .{ }^{\mathrm{b}}$ Not measured.

The ET rates are known to decrease with the distance (or thickenss), $L$, between redox sites according to an exponential law, $k_{\text {app }} \propto \exp (-\beta L)$, where $\beta$ is the decay coefficient. ${ }^{28)}$ From the plots of $\ln \left(k_{\text {app }}\right)$ as a function of the film thickness, the $\beta$ values are obtained as $0.014 \AA^{-1}$ and 0.010 $\AA^{-1}$ for the films of $\mathbf{1 1}$ and $\mathbf{1 2}$, respectively, which are relatively small. $\mathrm{We}^{29)}$ and other groups ${ }^{30)-}$ ${ }^{32)}$ have also reported similar small $\beta$ values for metal complex polymer wires connected by the coordination bonds or hydrogen bonding. By the theoretical-experimental collaboration to explain the long-range electron transfer but the low conductnace,, the "stepping-stone mechanism", was proposed for the metal complex multilayer films, where the alignment of the site potentials forms a narrow band around Fermi level, making rosonant tunneling possible. ${ }^{29)}$

\section{Ion permeability within redox-active} multilayer films. Electrochemical behaviors of the present multilayer films are analogous to the redox-active polymers obtained from polyelectrolyte multilayers or elecropolymerization of redox-active molecules. 33), 34) Compared to these polymer-based materials having randomly arranged structures, the significant difference arises from a well-ordered network structures in a nanometer range based on the coordination bond between the rod-shaped complex units and zirconium(IV) ions in the LbL multilayer films. Therefore, even the numbers of layers go up to 60 layers, the LbL films are still electrochemically active. In order to investigate the ion permeability in the films, electrochemical quartz crystal microbalance (EQCM) experiments were performed for the ITO $\|(\mathbf{1 1})_{\mathrm{n}}$ films in $0.1 \mathrm{M} \mathrm{HClO}_{4}$ in $\mathrm{CH}_{3} \mathrm{CN}$ using ITO-coated quartz crystal resonator electrode. ${ }^{35)}$ Upon the successive one-electron oxidations, a decrease in frequency $(\Delta \mathrm{F})$ was observed (Fig. 5), which indicates that the anions were penetrated into the $\mathrm{Ru}$
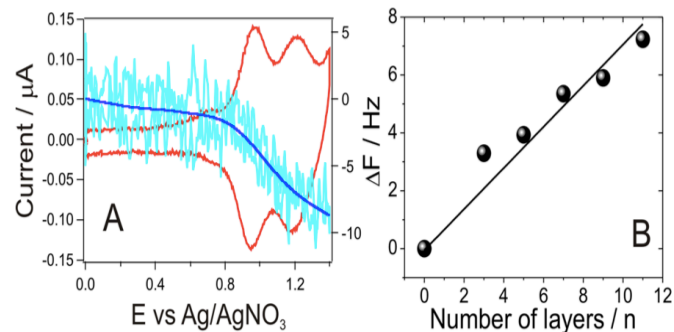

Fig. 5. EQCM response of ITO $\|(\mathbf{1 1})_{9}$ film, together with $\mathrm{CV}$ at $50 \mathrm{mV} \cdot \mathrm{s}^{-1}$ in $\mathrm{CH}_{3} \mathrm{CN}\left(0.1 \mathrm{M} \mathrm{HClO}_{4}\right)$, and plots of frequency change vs the number of layers. (Reprinted with the permission from ref. 35 . Copyright 2016, RCS) 
LbL network films to compensate the surface charge on the electrode. The plot of the frequency change vs the number of the layers showed a linear increase with a slope of $3.74 \mathrm{ng} \cdot \mathrm{cm}^{-2}$ per layer (Fig. 5B). The ion storage ability of ITO $\|(\mathbf{1 1})_{n}$ films in the coordination network layer structure was applied to the electrochemical redox capacitor in a scalable manner, and a specific capacitance of $95.3 \mathrm{~F} \cdot \mathrm{g}^{-1}$ was obtained for ITO $\|(\mathbf{1 1})_{65}$ multilayer film. ${ }^{35)}$

Hetero LbL multilayer films. One of the merits for the coordination LbL growth is to fabricate the different sequential molecular films by controlling the molecular sequence and the number of layers. Since the difference in redox potentials between the complex units $\mathbf{1 1}$ and $\mathbf{1 2}$ was $\sim 0.7 \mathrm{~V}$, the ET rectification was examined. ${ }^{27)}$ Changing the number of layers, $n$, in heterolayer films, ITO $\|(\mathbf{1 1})_{\mathrm{n}} \mid(\mathbf{1 2})_{\mathrm{n}}$, the ET blocking by inner layer film of $\mathbf{1 1}$ occurred in the case of the number of layers $n \geq 2$, and the catalytic wave was
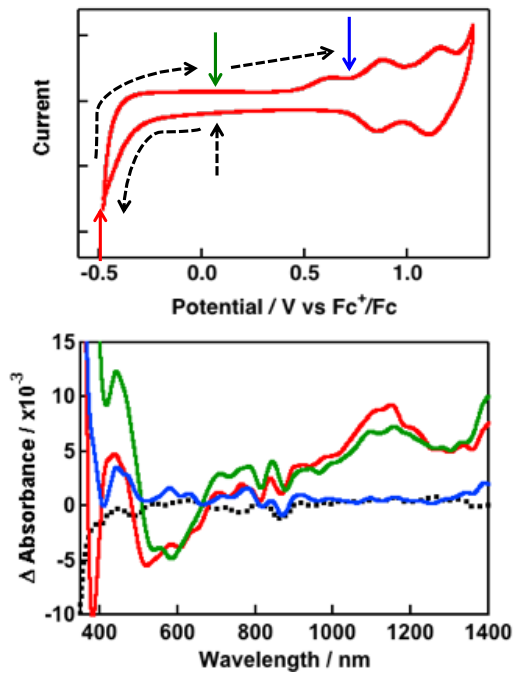

Fig. 6. CV response and differential UV/Vis and NIR spectroelectrochemistry of ITO $\|(\mathbf{1 1})_{4} \mid(\mathbf{1 2})_{4}$ in $\mathrm{CH}_{3} \mathrm{CN}\left(0.1 \mathrm{M} \mathrm{HClO}_{4}\right)$ by the applied potential shown by arrows in CV. (Reprinted with the permission from ref. 27 . Copyright 2016, Wiley-VCH) observed. In the case of $n=1$ in the ITO $\|(\mathbf{1 1}) \mid(\mathbf{1 2})$, the direct electron transfer from the outer layer $\mathbf{1 2}$ took place through the ET tunnelling since the molecular thickness of $\mathbf{1 1}$ is $1.9 \mathrm{~nm}$, however over the layer number $\mathrm{n} \geq 2$, the ET was blocked by the potential barrier between $\mathbf{1 1}$ and $\mathbf{1 2}$. The mixed-valence state of $\mathbf{1 2}$ showed a characteristic strong IVCT band at $1140 \mathrm{~nm}$, which became a good marker for the charging state of the outer $\mathbf{1 2}$ film. The differential UV/Vis and NIR spectra of ITO $\|(\mathbf{1 1})_{n} \mid(12)_{n}$ heterofilm in $\mathrm{CH}_{3} \mathrm{CN}(0.1 \mathrm{M}$ $\mathrm{HClO}_{4}$ ) ws shown in Fig. 6 at different applied potentials, starting from $0.06 \mathrm{~V} \rightarrow-0.54 \mathrm{~V} \rightarrow 0 \mathrm{~V}$ $\rightarrow+0.64 \mathrm{~V}$ vs $\mathrm{Fc} / \mathrm{Fc}^{+}$. At the open circuit potential, there is no NIR peak at $1140 \mathrm{~nm}$. When the potential was applied at $-0.54 \mathrm{~V}$, the IVCT band at $1140 \mathrm{~nm}$ appeared, and this IVCT band remained until the potential being applied beyond the catalytic wave at $+0.64 \mathrm{~V}$. This result indicates that the charge was stored on the outer $\mathbf{1 2}$ layered film as the mixed-valence state of $\mathbf{1 2}$ because of the ET rectification in ITO $\|(\mathbf{1 1})_{\mathrm{n}} \mid(\mathbf{1 2})_{\mathrm{n}}$ heterofilm. Therefore, two different states were

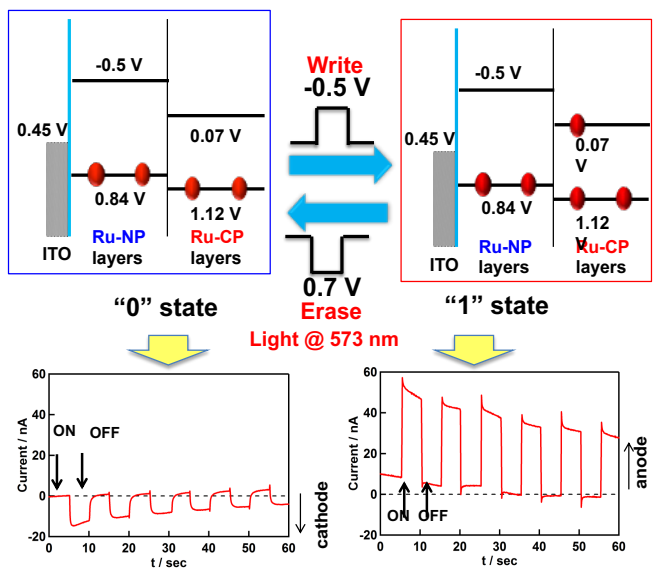

Fig. 7. Energy profile of two "0" and " 1 " states on ITO $\|(\mathbf{1 1})_{4} \mid(\mathbf{1 2})_{4}$ heterofilm and their photocurrent responses under photoirradiation at $573 \mathrm{~nm}$. (Reprinted with the permission from ref. 27. Copyright 2016, Wiley-VCH) 
addressed, depending on the oxidized or mixedvalence state of the outer 12 layer. This two states can be switched by the applied voltage of $-0.5 \mathrm{~V}$ or $+0.7 \mathrm{~V}$. Surprisingly, the two states can be read out by the direction of photocurrent; i.e., cathodic photocurrent for the oxidied state of $\mathbf{1 2}$, on the other hand the anodic photocurrent for the mixed-valence state. Sequntial write/read operation in the ITO $\|(\mathbf{1 1})_{4} \mid(\mathbf{1 2})_{4}$ heterolayer film exhibits a stable response, which provides the basis for the molecular-based memory devices. ${ }^{27)}$ Homolayer films of either ITO $\|(\mathbf{1 1})_{\mathrm{n}}$ or ITO $\|(\mathbf{1 2})_{\mathrm{n}}$ did not show little photoresponse under the same photoirradiation condiiton, which suggests the importance of heterojunction for the photoelectric response in the molecular films, which is relevant to the $p n$ junction in doped $\mathrm{Si}$ based semiconductors.

\section{PCET reaction in LbL multilayer films and its} application to proton-rocking-chair type redox capacitor. The Ru complexes 14, 15, and 16 in Scheme 7 were attached to an ITO electrode surface by the coordination LbL growth between phosphonate groups on the rod-shaped dinuclear $\mathrm{Ru}$ complex and zirconium(IV) ions. For the monolayer film of $\mathbf{1 5}$ and $\mathbf{1 6}$ on the ITO, one two-

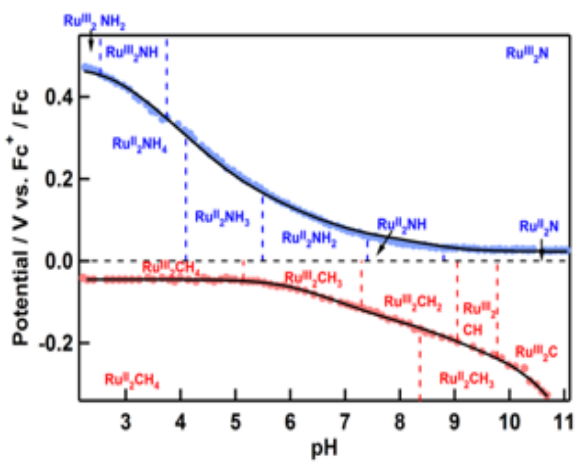

Fig. 8. Pourbaix diagram of $\mathbf{1 5}$ and $\mathbf{1 6}$ in $\mathrm{CH}_{3} \mathrm{CN} / \mathrm{BR}$ buffer, where all phosphonic acid groups are ethyl group protected. (Reprinted with permission from Ref. 36. Copyright 2018, ACS)

electron $\quad \mathrm{Ru}(\mathrm{II})-\mathrm{Ru}(\mathrm{II}) / \mathrm{Ru}(\mathrm{III})-\mathrm{Ru}(\mathrm{III}) \quad$ redox wave was observed at $0.33 \mathrm{~V}$ for $\mathbf{1 5}$ and $-0.21 \mathrm{~V}$ vs $\mathrm{Fc} / \mathrm{Fc}^{+}$for $\mathbf{1 6}$ with the surface coverage of (4.0 $\pm 0.2) \times 10^{-11} \mathrm{~mol} \cdot \mathrm{cm}^{-2}$ for both complexes in a neutral aqueous solution of $0.1 \mathrm{M} \mathrm{NaClO}_{4}$. The isolated original oxidation states are $\mathrm{Ru}(\mathrm{II})$ $\mathrm{Ru}(\mathrm{II})$ for $\mathbf{1 4}$ and $\mathbf{1 5}$, whereas $\mathrm{Ru}(\mathrm{III})-\mathrm{Ru}(\mathrm{III})$ for 16. The proton-electron equilibria for the twoelectron system of 14 -16 in Scheme 9 were analyzed from the plots of half-wave potntials vs $\mathrm{pH}$ as shown in Fig. 8. The pKa values for $\mathbf{1 5}$ and 16 were collected in Table 2. The $\mathrm{p} K_{\mathrm{a}}$ values of 15 are in the range of 4.2 to 8.5 for the $\mathrm{Ru}(\mathrm{II})$

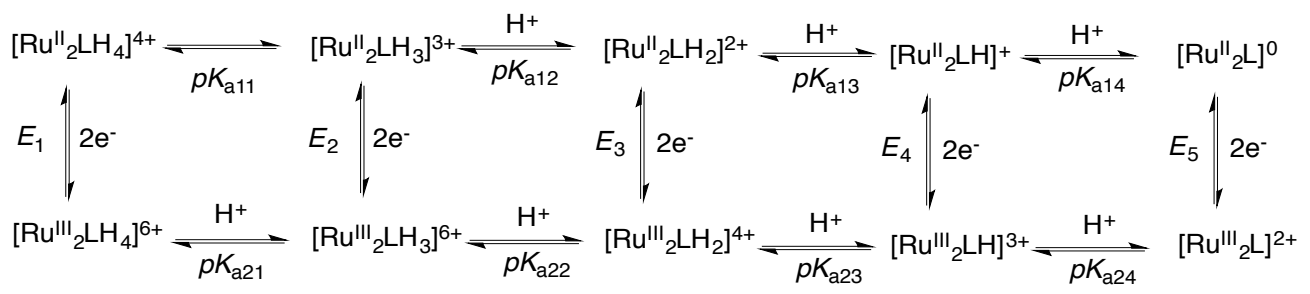

Scheme 9. Schematic illustration of the electron-proton equilibria in the Ru complexes 15, 16.

Table 2. $\mathrm{p} K_{\mathrm{a}}$ values for dinuclear Ru complex units in $\mathrm{CH}_{3} \mathrm{CN} /$ Britton-Robinson (BR) buffer.

\begin{tabular}{lllllllll}
\hline \multirow{2}{*}{ Complex } & \multicolumn{3}{c}{$\mathrm{Ru}(\mathrm{II})$} & \multicolumn{7}{c}{$\mathrm{Ru}(\mathrm{III})$} \\
\cline { 2 - 9 } & $\mathrm{p} K_{\mathrm{a} 11}$ & $\mathrm{p} K_{\mathrm{a} 12}$ & $\mathrm{p} K_{\mathrm{a} 13}$ & $\mathrm{p} K_{\mathrm{a} 14}$ & $\mathrm{p} K_{\mathrm{a} 21}$ & $\mathrm{p} K_{\mathrm{a} 22}$ & $\mathrm{p} K_{\mathrm{a} 23}$ & $\mathrm{p} K_{\mathrm{a} 24}$ \\
\hline $\mathbf{1 5}$ & 4.2 & 5.3 & 7.4 & 8.5 & & $<2.3$ & 2.5 & 3.8 \\
$\mathbf{1 6}$ & 8.4 & $>11.0$ & & & 5.2 & 7.3 & 9.1 & 9.8 \\
\hline
\end{tabular}


oxidation state, and the range of $<2.3$ to 3.8 for the $\mathrm{Ru}(\mathrm{III})$. On the other hand, the $\mathrm{p} K_{\mathrm{a}}$ values of $\mathbf{1 6}$ are in sharp contrast to those for 15: i.e. for the $\mathrm{Ru}(\mathrm{II})$ state in the $\mathrm{p} K_{\mathrm{a}}$ range of 8.4 to $>11$, and the range of 5.2 to 9.8 for the $\mathrm{Ru}(\mathrm{III})$ one (see Table 2). In order to confirm the proton

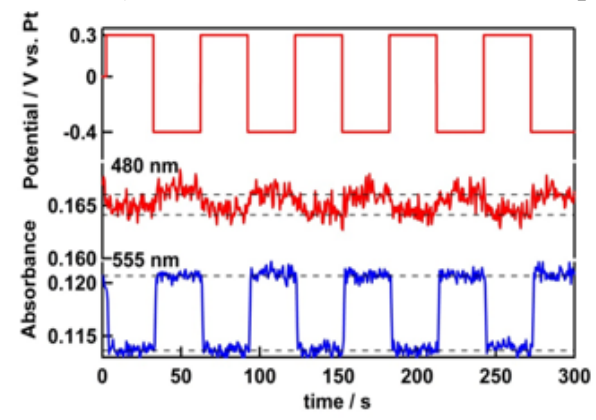

Fig. 9. Changes of the UV/Vis absorbance at 555 $\mathrm{nm}$ (bottom) and $480 \mathrm{~nm}$ (middle) upon the application of continuous potential pulse sequence for ITO $\|(\mathbf{1 5})_{10}$ in $0.1 \mathrm{M} \mathrm{NaClO}_{4}$ in the presence of the $\mathrm{pH}$ indicator. (Reprinted with permission from Ref. 36. Copyright 2018, ACS)

movement in the ITO $\|(\mathbf{1 5})_{10}$ multilayer films upon the $\mathrm{Ru}(\mathrm{II}) / \mathrm{Ru}(\mathrm{III})$ oxidation, the electrochromic response of the ITO $\|(\mathbf{1 5})_{10}$ multilayer film with 5(6)-carboxyfluorescein in aqueous solution was measured. The monitored wavelengths in the thin-layer spectroelectrochemistry for the ITO $\|(\mathbf{1 5})_{10}$ film were carefully chosen as 480 and $555 \mathrm{~nm}$, given that (i) the former represents the isosbestic point for the $\mathrm{Ru}(\mathrm{II}) / \mathrm{Ru}(\mathrm{III})$ oxidation process, that is, the $\mathrm{pH}$ change can be monitored exclusively using the $\mathrm{pH}$ indicator UV probe 5(6)- carboxyfluorescein; (ii) the latter represents the spectral change for the MLCT transition on the $\mathrm{Ru}(\mathrm{II}) / \mathrm{Ru}(\mathrm{III})$ process. Upon the application of the potential pulse ( $30 \mathrm{~s}$ interval) from $-0.4 \mathrm{~V}$ to $+0.3 \mathrm{~V} \mathrm{vs} \mathrm{Pt}$, the MLCT absorbance at $555 \mathrm{~nm}$ decreased due to the oxidation of the $\mathrm{Ru}$ (II) to $\mathrm{Ru}$ (III) in 15.(Fig. 9) At the same time, a small

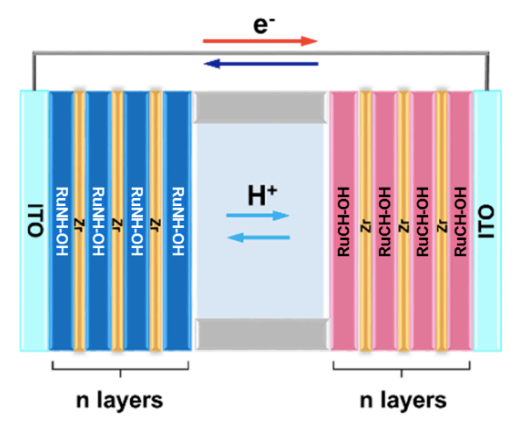

Scheme 10. Schematic representation of the twoelectrode cell based on ITO $\|(\mathbf{1 5})_{\mathrm{n}}$ and ITO $\|(\mathbf{1 6})_{\mathrm{n}}$. (Reprinted with permission from Ref. 36. Copyright 2018, ACS)

decrease of the absorbance at $480 \mathrm{~nm}$ was observed, which corresponds to the increase of the proton concentration, as a result of the proton release from ITO-immobilized $\mathbf{1 5}$. The successive applied potential pulses showed a reproducible absorbance change at both 555 and $480 \mathrm{~nm}$.

By utilize the large $\mathrm{p} K_{\mathrm{a}}$ and the potential difference between 15 and 16, proton-rockingchair type redox capacitor was constructed as a two-electrode system consisted of two ITO $\|(\mathbf{1 5})_{n}$ and ITO $\|(\mathbf{1 6})_{\mathrm{n}}$ (n: number of layers; $\mathrm{n}=10,20$, 30 40, and 50 layers) sandwiching anqueous solution of $\mathrm{NaClO}_{4}$.(Scheme 10) Under



Fig. 10. Effect of the number of layers on the galvanostatic charge/discharge curves of ITO $\left\|(\mathbf{1 5})_{\mathrm{n}} / /(\mathbf{1 6})_{\mathrm{n}}\right\|$ ITO $(\mathrm{n}=10-50)$. (Reprinted with permission from Ref. 36. Copyright 2018, ACS) 
galvanostatic conditions on the two-electrode cell, stable, reversible, and repeatable charging/discharging processes occurred. The capacitance increased linearly with an increasing number of LbL layers. When the N-H proton sites were protected by N-methylation in $\mathbf{1 5}$ and $\mathbf{1 6}$, the capacitance decreased by $77 \%$. Thus, the protons should behave as more efficient charge carriers than sodium ions in the electrolyte solution. ${ }^{36)}$

\section{Conclusion}

Redox-active ruthenium complexes have been extensively studied in the 1970 s - 90s from the viewpoint of fundamental electron transfer reactions. Based on the basic knowledge, the construction of molecular electronic devices using various molecules on a surface has become a rage as a bottom-up approach in the 2000s. Around that time, my research direction turned to a new challenge toward molecular devices; i.e., surface coordination chemistry for the construction of nanostructures using redox-active complexes. While the selection of anchoring groups depends on the target substrate surface, the coordination $\mathrm{LbL}$ growth method is now becoming a routine protocol to build the wellordered coordination network structure. I found the molecular orientation of the first primer layer plays an important role. ${ }^{22)}$ The use of multipod anchored molecules makes the molecular orientation rigid on the surface to obtain stable molecular modified film. Further, the judicious selection of the complex units for the hetero LbL films makes it possible to produce a variety of functional composite films in a combinatorial manner such as the diode by ET rectification or charge storage through potential gradient. ${ }^{27)}$ Therefore, the redox-active coordination LbL films on the electrode will have potential applications including catalysis, energy and biosensor devices, ion permeability for batteries, etc. While the example of redox-active SURMOF is sparse, but the redox-active coordination $\mathrm{LbL}$ films are intimately related to redox-active SURMOF, and both will be attracting interest as an electrode functionalization sometime in the near future.

\section{Acknowledgements}

I express my sincere thanks to Prof. Takeko Matsumura-Inoue, Prof. A. M. Bond, Prof. T. E. Mallouk, Prof. A. B. P. Lever, Prof. Kenji Kano, Prof. Koji Tanaka, Prof. Koichi Nozaki, Prof. Takeshi Ohno, Prof. Takao Ishida, Dr. Takayoshi Sasaki, late Prof. Toshio Tanaka for their valuable guidance and fruitful discussions. I have done some my work described here only by standing on their shoulders. I also thank Dr. Katsuaki Kobayashi, Prof. Katsuhiko Kanaizuka, Dr. Hiroaki Ozawa, and all of my students and coauthors in my papers for their great help and their contribution. I acknowledge the financial support from MEXT for a Grant-in-Aid for Scientific Research, JP17H05383 (Coordination Asymmetry), and the Institute of Science and Engineering at Chuo University.

\section{References}

1) J. Liu and C. Woll, Chem Soc Rev, 46, 5730 (2017).

2) M. Haga, T. Matsumura-Inoue, K. Shimizu and G. P. Sato, J. Chem. Soc. Dalton Trans., 371 (1989).

3) J. Chatt, C. T. Kan, G. J. Leigh, C. J. Pickett and D. R. Stanley, J. Chem. Soc. Dalton Trans., 2032 (1980).

4) A. B. P. Lever, Inorg. Chem., 29, 1271 (1990).

5) W.-W. Yang, Y.-W. Zhong, S. Yoshikawa, J.-Y. Shao, S. Masaoka, K. Sakai, J. Yao and M. Haga, Inorg. Chem., 51, 890 (2012).

6) M. H. Huynh and T. J. Meyer, Chem. Rev., 107, 5004 (2007). 
7) A. M. Bond and M. Haga, Inorg. Chem., 25, 4507 (1986).

8) M. Haga, T. Ano, K. Kano and S. Yamabe, Inorg. Chem., 30, 3843 (1991).

9) X. Xiaoming, M. Haga, T. Matsumura-Inoue, Y. $\mathrm{Ru}, \mathrm{A}$. W. Addison and K. Kano, J. Chem. Soc. Dalton Trans., 2477 (1993).

10) M. Haga, T. Ano, T. Ishizaki, K. Kano, K. Nozaki and T. Ohno, J. Chem. Soc. Dalton Trans., 263 (1994).

11) M. Haga, M. M. Ali, S. Koseki, K. Fujimoto, A. Yoshimura, K. Nozaki, T. Ohno, K. Nakajima and D. J. Stufkens, Inorg. Chem., 35, 3335 (1996).

12) J. J. Warren, T. A. Tronic and J. M. Mayer, Chem. Rev., 110, 6961 (2010).

13) K. Kobayashi, M. Ishikubo, K. Kanaizuka, K. Kosuge, S. Masaoka, K. Sakai, K. Nozaki and M. Haga, Chem. - Eur. J., 17, 6954 (2011).

14) C. G. Cameron, T. J. Pittman and P. G. Pickup, J. Phys. Chem. B, 105, 8838 (2001).

15) M. Haga, M. M. Ali and R. Arakawa, Angew. Chem. Int. Ed., 35, 76 (1996).

16) B. Fabre, Chem. Rev., 116, 4808 (2016).

17) A. Ulman, Chem. Rev., 96, 1533 (1996).

18) G. Cao, H.-G. Hong and T. E. Mallouk, Acc. Chem. Res., 25, 420 (1992).

19) M. Felderhoff, S. Heinen, N. Molisho, S. Webersinn and L. Walder, Hel. Chim. Acta, 83, 181 (2000).

20) T. Morotti, V. Calabrese, M. Cavazzine, D. Pedron, M. Cozzuol, A. Licciardello, N. Tuccitto and S. Quici, Dalton Trans., 2974 (2008).

21) R. S. Loewe, A. Ambroise, K. Muthukumaran, K. Padmaja, A. B. Lysenko, G. Mathur, Q. Li, D. F. Bocian, V. Misra and J. S. Lindsey, J. Org. Chem., 69, 1453 (2004).

22) (a) M. Haga, K. Kobayashi and K. Terada, Coord. Chem. Rev., 251, 2688 (2007). (b)S. A. Paniagua, A. J. Giordano, O. L. Smith, S. Barlow, H. Li, N. R. Armstrong, J. E. Pemberton, J. L. Bredas, D. Ginger and S. R. Marder, Chem. Rev., 116, 7117 (2016).

23) C. Queffelec, M. Petit, P. Janvier, D. A. Knight and B. Bujoli, Chem Rev, 112, 3777 (2012).

24) E. Galoppini, W. Guo, W. Zhang, P. G. Hoertz, P. $\mathrm{Qu}$ and G. J. Meyer, J. Amer. Chem. Soc., 124, 7801 (2002).

25) K. Nikitin and D. Fitzmaurice, J. Amer. Chem. Soc., 127, 8067 (2005).

26) K. Muthukumaran, R. S. Loewe, A. Ambroise, S. Tamaru, Q. Li, G. Mathur, D. F. Bocian, V. Misra and J. S. Lindsey, J. Org. Chem., 69, 1444 (2004).

27) (a) T. Nagashima, H. Ozawa, T. Suzuki, T. Nakabayashi, K. Kanaizuka and M. Haga, Chem. Eur. J., 22, 1658 (2016). (b)T. Nagashima, T. Suzuki, H. Ozawa, T. Nakabayashi, M. Oyama, T. Ishida and M. Haga, Electrochim. Acta, 204,
235 (2016).

28) J.-P. Launay and M. Verdaguer, Electrons in Molecules:From Basic Principles to Molecular Electronics, Oxford Univ. Press, Oxford, UK, 2018.

29) K. Terada, H. Nakamura, K. Kanaizuka, M. Haga, Y. Asai and T. Ishida, ACS Nano, 6, 1988 (2012).

30) N. Tuccitto, V. Ferri, M. Cavazzini, S. Quici, G. Zhavnerko, A. Licciardello and M. A. Rampi, Nature Mater, 8, 41 (2009).

31) (a) Y. Nishimori, K. Kanaizuka, T. Kurita, T. Nagatsu, Y. Segawa, F. Toshimitsu, S. Muratsugu, M. Utsuya, S. Kume, M. Murata and H. Nishihara, Chem. Asian J., 4, 1361 (20090. (b) H. Maeda, R. Sakamoto and H. Nishihara, Polymer, 54, 4383 (2013).

32) Z. Karipidou, B. Branchi, M. Sarpasan, N. Knorr, V. Rodin, P. Friederich, T. Neumann, V. Meded, S. Rosselli, G. Nelles, W. Wenzel, M. A. Rampi and F. von Wrochem, Adv Mater, 28, 3473 (2016).

33) T. R. Farhat and J. B. Schlenoff, J. Amer. Chem.Soc., 125, 4627 (2003).

34) H. D. Abruna, P. Denisevich, M. Umana, T. J. Meyer and R. W. Murray, J. Amer. Chem. Soc., 103, 1 (1981).

35) V. Kaliginedi, H. Ozawa, A. Kuzume, S. Maharajan, I. V. Pobelov, N. H. Kwon, M. Mohos, P. Broekmann, K. M. Fromm, M. A. Haga and T. Wandlowski, Nanoscale, 7, 17685 (2015).

36) K.Yoshikawa, D. Motoyama, Y. Hiruma, H. Ozawa, S. Nagano and M.Haga, ACS Appl. Mater. Interfaces, 10, 26990 (2018) 